\title{
AVALIAÇÃO DA EDUCAÇÃO SUPERIOR E PLANO NACIONAL DE EDUCAÇÃO: TENSÕES, MUDANÇAS E PERSPECTIVAS
}

\author{
LÚCIA MARIA DE AsSIS \\ Universidade Federal de Goiás (UFG), Goiânia, Goiás, Brasil \\ Aline Fagner de CARVAlho e Costa \\ Programa de Educação Ambiental de Educadores (PEAT), Oriximiná, Pará, Brasil \\ Pedro IsaAc XIMENes LoPes \\ Universidade Federal do Rio Grande do Norte (UFRN), Natal, Rio Grande do \\ Norte, Brasil \\ Universidade Potiguar (UnP), Natal, Rio Grande do Norte, Brasil \\ Daniela Fernandes GOMES \\ Instituto Federal do Norte de Minas Gerais (IFNMG), Montes Claros, Minas \\ Gerais, Brasil
}

\begin{abstract}
Resumo: Este estudo tem como objetivo problematizar a dinâmica das políticas públicas voltadas para avaliação, regulação e supervisão da Educação Superior brasileira, ao relacioná-las às Metas 12, 13 e 14 do Plano Nacional de Educação (PNE) e, especialmente, às estratégias relativas ao Sistema Nacional de Avaliação da Educação Superior (Sinaes), Lei n. 10.861 de 2004. Trata-se de um estudo teórico e documental, ancorado em Dourado (2017 e 2018); Barreyro e Rothen (2006 e 2011); Dias Sobrinho (2010); Amaral (2016 e 2019), dentre outros, além de textos normativos sobre o Sinaes. O estudo revelou que o campo da avaliação da Educação superior vem passando por processos de flexibilização e (des) regulamentação dos atos autorizativos, a partir de mudanças que intensificam a (de)formação do Sinaes em seu ciclo da política. Todas essas mudanças, atravessadas por tensões, disputas e embates desde a Lei 13.005 de 2014 do PNE, são marcadas e influenciadas por um cenário político instável e desfavorável às políticas sociais e educacionais.
\end{abstract}

Palavras-chave: Plano Nacional de Educação. Educação superior. Avaliação. Sinaes.

\section{INTRODUÇÃO}

Este estudo consiste na apresentação de dados parciais, resultantes do projeto de pesquisa "Expansão e qualidade da educação superior no contexto do Plano Nacional de Educação (2014-2024): tensões, limites e perspectivas" ${ }^{\prime \prime}$, e tem como objetivo problematizar a dinâmica das políticas públicas voltadas para avaliação, regulação e 
supervisão da Educação Superior brasileira. Visa ainda a relacioná-las às Metas 12, 13 e 14 do Plano Nacional de Educação (PNE) e, especialmente, às estratégias nelas presentes que se atentam ao Sistema Nacional de Avaliação da Educação Superior (Sinaes), Lei n. 10.861 de 2004. Proposto já no primeiro mandato de Lula, o Sinaes estabelece princípios e promessas para uma avaliação da Educação Superior com predomínio de aspectos formativos sobre os somativos. Embora a Lei original de 2004 permaneça intocada e sua referência ainda esteja presente no marco legal para o campo da educação superior, vêse que o Sinaes tem se ajustado às demandas e disputas emergentes no curso da história recente, perceptível nos sucessivos Decretos que dela se desdobraram.

A Lei n. 13.005 , de 25 de junho de 2014 (PNE 2014-2024), por sua vez, também resulta de intensas discussões e embates políticos e ideológicos em torno da concepção de Estado e de educação em disputa naquele momento. O Plano apresenta metas e estratégias que vislumbram elevar a qualidade da educação, tendo como parâmetros de análises os resultados obtidos em amplos processos de avaliação estabelecidos como políticas educacionais que tiveram origem nos anos $1980^{2}$. Especialmente as estratégias 12.19 e 13.1 do PNE propõem reestruturar, com ênfase na melhoria de prazos e qualidade da decisão, em dois anos (portanto, em 2016), os procedimentos adotados na área de avaliação, regulação e supervisão de cursos e Instituições de Educação Superior do sistema federal de ensino. As estratégias 13.1 a 13.8 também indicam os processos e resultados da avaliação, regulação e supervisão da educação superior como política a ser aprimorada, fortalecida e ampliada, com destaque ao Exame Nacional de Desempenho de Estudantes (Enade) e aos processos de auto avaliação institucional conduzidos por Comissões Próprias de Avaliação (CPA) ${ }^{3}$.

A contar de 2014, primeiro ano de vigência do PNE, as disputas do e no campo político se intensificam com a reeleição da Presidenta Dilma Rousseff ${ }^{4}$. Visando favorecer a compreensão do leitor, organizamos os objetivos e reflexões apresentados na exposição deste artigo em dois períodos: 1. período do segundo mandato de Dilma Rousseff (20152016), com análise das tendências e rupturas com seu mandato anterior (2011-2014), apresentadas a partir da proposta de criação do Instituto Nacional de Supervisão e Avaliação da Educação Superior (Insaes); 2. período Michel Temer (2016-2018), com análise das sucessivas alterações no marco regulatório para a educação superior e sua avaliação, realizada em 2016 e 2017, cuja tônica recai na desregulamentação e flexibilização do sistema. Nas considerações finais, explicita-se brevemente como o primeiro ano do governo Bolsonaro impactou as políticas educacionais para educação superior pública, sinalizando um horizonte pouco favorável para o alcance das Metas do PNE (2014-2024), sobretudo no que se refere à sua avaliação e expansão.

\section{O GOVERNO DILMA ROUSSEFF E O PROJETO DO INSTITUTO NACIONAL DE SUPERVISÃO E} AVALIAÇÃO DA EDUCAÇÃO SUPERIOR (INSAES)

Ao adotar, nos anos de 1990, a privatização como regra nas diversas esferas das áreas econômica e social em detrimento do protagonismo da oferta pública, o Estado brasileiro sinalizou para a ênfase nas funções de planejamento, regulamentação e fiscalização, mediante agências reguladoras. A crise estrutural do capital pôs em alerta 
modelo de financeirização da educação superior brasileira privada, capturada por poderosos conglomerados de investimentos rentistas. Percebeu-se que a constituição de um mercado na educação superior, sem efetiva regulação e controle, poderia colocar em risco a sua efetividade na formação dos estudantes e na realização de pesquisa e extensão. Assim, a relação mercado e educação superior no Brasil se tornou alvo do primeiro Governo Dilma Rousseff (2011-2014), com o intuito de estabelecer novo arranjo institucional no marco regulatório, o que culminou, em 2012, com a proposta de criação do Instituto Nacional de Supervisão e Avaliação da Educação Superior (Insaes), por meio do Projeto de Lei no 4.372/2012. O objetivo foi constituir uma autarquia responsável pela avaliação, regulação, supervisão e acreditação das instituições e cursos de graduação, evidenciando similitudes com formato e estrutura de agência reguladora, como regime colegiado, funções de fiscalização, imposição de taxas, aplicação de multas e constituição de um corpo técnico próprio.

Essa perspectiva representava uma confluência com a macrotendência do capitalismo, baseado em uma economia de mercado planejada e administrada pelo Estado, sem romper, no entanto, com a hegemonia do grande capital. Isto é, o fortalecimento institucional no âmbito da organização e gestão estatal não seria incompatível com a primazia do segmento privado na oferta de ensino, uma vez que o Estado, reconhecendo a centralidade do conhecimento no desenvolvimento e da movimentação econômica gerada pelos serviços educacionais, estaria apenas exercendo papel normativo e regulador, planejando e fiscalizando. Por outro lado, não estaria obstruindo o processo de privatização, mantendo o controle do crescimento do setor privado-mercantil, mas sem estatizar a sua expansão.

O Projeto Insaes, porém, enfrentou dois blocos de resistência. De um lado, o setor privado se posicionava contrário à possibilidade de maior regulação e supervisão sobre seus negócios, destacando-se a atuação da Confederação Nacional dos Estabelecimentos de Ensino (Confenen), da Federação Nacional das Escolas Particulares (Fenep), da Associação Brasileira de Mantenedoras de Ensino Superior (Abmes) e da bancada de parlamentares membros dos partidos defensores de interesses privatistas. Do outro, entidades públicas, como o INEP e a Conaes, temiam a secundarização e o desmonte da avaliação já desenvolvida no âmbito do Sinaes. A Câmara dos Deputados foi o lócus de concretude dos embates decisórios acerca do Projeto Insaes. Em sua essência, a discussão expôs o conflito de interesses acerca de qual seria o modelo de educação superior e, consequentemente, gerou uma disputa em torno de que projeto de sociedade se pretendia ter. Dessa forma, o Projeto Insaes não seguiu adiante.

Com a reeleição de Dilma Rousseff para um segundo mandato (2015-2018), iniciou-se o processo que culminou com o seu impeachment em 2016. A crise institucional instalada fez com que a coalização multipartidária, liderada pelo PT e o PMDB fosse se desagregando pouco a pouco e, dessa forma, ficou evidente a motivação política de não levar o Projeto Insaes adiante, resultado de uma decisão do grupo de oposição ao Governo, não relacionada ao valor da ação pública. A obstaculização desse projeto foi mais uma forma deliberada de mostrar força no embate existente no campo político.

Diante desse contexto, grande parte do PMDB reconstruiu a representação acerca dos problemas nacionais, das soluções e de suas consequências, e passou a defender a austeridade fiscal que seria implementada no período de Michel Temer (20162018). 
O PERÍODO MICHEL TEMER: TENDÊNCIAS À (DES) REGULAÇÃO DA EDUCAÇÃO SUPERIOR COM FLEXIBILIZAÇÃO DE PROCEDIMENTOS E SUBJETIVIDADE NA AVALIAÇÃO

No ano de 2016 e alinhando-se à estratégia 12.19 do PNE, o Decreto no 8.754, de 10 de maio de 2016, implementou muitas mudanças ao Decreto n. 5.773 de 2006, ao alterar 25 dos seus 79 artigos. Durante mais de uma década, o Decreto no 5.773 articulou do processo de avaliação ao de regulação e supervisão no Brasil, sendo por isso chamado de Decreto Ponte 5 .

Nas alterações de 2016 já se anunciava a simplificação de processos de regulação, principalmente para as universidades, tanto públicas quanto privadas, e institutos federais ${ }^{6}$. A ênfase das alterações estava nos prazos e na qualidade da decisão expressa nos atos autorizativos, além de regulamento para simplificar processos de credenciamento para Educação a Distância (EaD). Sendo assim, para IES com desempenhos comprovados de alta qualidade, anunciava-se a possibilidade de processos simplificados para transferência de mantença entre pessoas jurídicas de um mesmo grupo empresarial. Prescrevia ainda que os institutos federais garantissem o itinerário formativo com oferta de cursos técnicos de nível básico (ensino médio) articulados aos cursos superiores. Neste decreto ampliam-se os prazos do credenciamento para IES e são excluídas as competências das Secretarias de Educação Profissional e de Educação a Distância, preservadas apenas em casos específicos e aplicados às Instituições Federais de Educação Superior.

Desta forma, evidencia-se no texto proposto pelo Decreto 8.754/2016 a consideração de índices e indicadores de qualidade para fundamentar os atos autorizativos para cursos e instituições. Além disto, detalham-se procedimentos de transferência de mantença, define-se como sendo de caráter optativo a participação de conselhos profissionais, aligeira-se o trabalho das comissões de especialistas, ampliando a dispensa de visita in loco e possibilitando, portanto, processos simplificados de autorização. Para a supervisão o Decreto de 2016 propõe apurar responsabilidades em avaliações insatisfatórias e aumento do prazo da caducidade da autorização de curso para dois anos e ainda determina que "o campus fora de sede integrará o conjunto da universidade e não gozará de prerrogativa de autonomia, ressalvados os campi de universidade federais que tiverem prerrogativas mencionadas em suas leis de criação" (BRASIL, 2016).

Contudo, em 2017, como resultado dos embates políticos que giraram em torno da interrupção do governo de Dilma Rousseff, efetivaram-se outras reformulações no processo avaliativo da Educação Superior que atingiram os decretos que operacionalizam o Sinaes de 2004.

Em 2017, o Decreto no 9.235, de 15 de dezembro ${ }^{7}$, revoga e substitui o Decreto Ponte $\mathrm{n}^{\circ} 5.773$, de 9 de maio de 2006, e os ajustes promovidos pelo Decreto 8.754/2016, que até então dispunham sobre o exercício das funções de regulação, supervisão e avaliação de instituições de educação superior e cursos superiores de graduação e sequenciais neste Sistema. Outros decretos revogados são: Decreto n. 5.686/2006 dispõe sobre Centros Universitários; Decreto n. 6.303/2007 sobre o credenciamento de Campus 
ASSIS, L. M. de , COSTA, A. L. C.; LOPES, P. I. X. GOMES, D. F.

e polos de cursos a distância; e Decreto n. 8.142/2013, com medidas acauteladoras do Fies, Prouni e outros.

O Decreto 9.235/2017 e as prescrições que dele se desdobraram operacionalizam a regulação do campo da educação superior brasileira a partir da dispensa da avaliação in loco para os atos de entrada de cursos em IES com Conceito Institucional (Cl) e Índice Geral de Cursos (IGC) maior ou igual a 3. Dessa forma, ficam condicionados a conceitos iguais ou superiores a 3 para cada um dos indicadores essenciais, que são retomados das versões originais do Sinaes. Este fato diminui a articulação entre as apreciações internas e externas e a consequente mobilização do corpo docente, favorável a um processo avaliativo integrado e global.

São muitas as consequências desse conjunto de alterações no processo de regulação e avaliação da educação superior. As instituições universitárias, públicas e privadas, tornam-se autônomas para credenciarem campi fora de sede. As instituições não universitárias também obtêm relativa autonomia diante de indicadores de alta qualidade para autorização de cursos e aditamento de vagas, além de registro de seus próprios diplomas em caso de avaliação de excelência. Os processos de transferências de mantença seguem com detalhamento de ações vedadas, como a transferência de cursos entre IES, divisão de mantidas, unificação de mantidas com mantenedoras diferentes e divisão de cursos numa mesma mantida.

Faculdades com a nota 5 na avaliação podem registrar diploma. Para que as Faculdades se transformem em Centros Universitários o corpo docente deve compor-se com no mínimo um quinto (1/5) em regime de trabalho integral e um terço $(1 / 3) \mathrm{com}$ formação stricto sensu (mestres e doutores/as), além de oito (8) graduações, Conceito Institucional (Cl) maior ou igual a 4 , extensão e pesquisa institucionalizadas, sem penalidades em 2 anos.

Em relação aos Centros Universitários, embora não tenham autonomia para abrir campi fora de sede, há um conjunto de simplificações dos processos de avaliação que diminuem as exigências nos atos de entrada, como, por exemplo, a dispensa de visita in loco em caso de excelência, abertura de cursos, aditamento de vagas e ampliação do tempo de vigência dos atos autorizativos do Poder Público (credenciamento e recredenciamento de IES e autorização, reconhecimento e renovação de reconhecimento de cursos). Para que os Centros Universitários se assumam como Universidades, a regulação traz como condicionante um corpo docente com um terço (1/3) tempo integral e um terço (1/3) stricto sensu; $60 \%$ de graduação satisfatório, 4 mestrados e 2 doutorados sem penalidades em 2 anos. No caso das Universidades, é concedida autonomia aos campifora de sede.

Houve aproximações e unificações entre os instrumentos para avaliação da educação presencial e a distância e instrumentos diferenciados e exclusivos para as licenciaturas, movimento previsto pelo PNE em vigor. As competências dos órgãos federais para educação superior são reestruturadas com diminuição do papel das Secretarias competentes (Educação Profissional e Técnica e Educação a Distância) do Ministério da Educação, além da reorganização das atribuições do INEP8.

Em 2017, as Portarias MEC n. ${ }^{0} 1.382^{9}$ e no $1.383^{10}$, ambas de 31 de outubro de 2017, aprovaram os indicadores dos instrumentos de avaliação externa a serem utilizados nos procedimentos de verificação in loco para a avaliação de IES e de cursos de graduação, respectivamente. Em seguida, em 01 de dezembro de 2017, a Diretoria de Avaliação da 
Educação Superior do Inep (Daes/Inep) publicou a Nota Técnica $n^{\circ}$ 16/2017/CGACGIES/DAES, que descreveu as principais alterações dos instrumentos, da escala de pontuação e de seus mecanismos, além de explicitar os critérios para a inserção e modificação de indicadores.

Dentre as principais alterações provenientes destes dispositivos legais e relativas aos instrumentos de avaliação externa de IES e cursos, pode-se mencionar: a separação dos instrumentos entre atos de entrada (credenciamento de IES e autorização de cursos) e atos de permanência (recredenciamento de IES e transformação de organização acadêmica, reconhecimento e renovação de reconhecimento de cursos); a unificação de instrumentos das modalidades presencial e a distância; o aumento da subjetividade dos avaliadores, com aumento dos critérios qualitativos e diminuição dos quantitativos; a mudança de informações solicitadas na análise preliminar e nas considerações finais; e a forma de solicitação dos requisitos legais e normativos, que não vigoram mais como exigências e, sim, na forma de atributos, como componentes da análise preliminar.

Outra mudança considerável refere-se à escala e aos critérios de qualidade que devem ser utilizados para atribuir os conceitos das dimensões avaliadas, sendo que a sua verificação passou a ser sustentada por "evidências". Assim, assumem destaque, na nova metodologia, os termos: atributos (caracterizam a qualidade do objeto de análise e são associados a um conceito); critérios aditivos (são atributos que suplementam a avaliação, integrando o critério de análise para os conceitos 4 e 5); e evidências (critérios de qualidade a serem verificados).

Neste sentido, observa-se uma mudança na lógica avaliativa, uma vez que os atributos, critérios aditivos e evidências adotados tornaram tanto os instrumentos como os procedimento de avaliação in loco mais subjetivos, valendo-se mais da percepção dos avaliadores e da capacidade de construir evidências (atas, relatórios, comprovantes etc.) da IES do que de dados e informações quantitativos. Como exemplo, podemos citar os indicadores relativos à titulação e regime de trabalho do corpo docente; coordenação de curso e as bibliografias básica e complementar, que antes possuíam critérios de análise totalmente quantitativos e objetivamente mensuráveis, foram alterados para serem mensurados de forma essencialmente qualitativa.

Algumas novidades na avaliação in loco incluem ainda o surgimento de novos instrumentos, como o Plano de Ação do Coordenador e o Plano de Trabalho do Professor, além de novos requisitos no que se refere aos docentes, como o cálculo e a inserção do tempo médio de permanência do corpo docente e a utilização do Indicador de Qualidade do Corpo Docente (IQCD) ${ }^{11}$.

Quanto a este indicador destaca-se que a titulação do corpo docente não conta mais no aspecto quantitativo da avaliação das dimensões, dos eixos ou dos conceitos finais de curso ou institucional. Segundo a Nota Técnica no 16/2017/CGACGIES/DAES, não é claramente definida a utilidade do IQCD, apenas é mencionado que seus resultados serão utilizados em estudos e pesquisas que, "para além da construção do conhecimento serão adotados para decisões futuras sobre os instrumentos, escalas e indicadores, bem como para subsídios regulatórios. "Trata-se, portanto, de mais um aspecto que reflete a flexibilização de pontos relativos à regulação das IES e que poderá impactar nas condições 
ASSIS, L. M. de , COSTA, A. L. C.; LOPES, P. I. X. GOMES, D. F.

de oferta e na qualidade de cursos, uma vez que a análise destas condições serão baseadas na maneira como os avaliadores descreverão a realidade observada, sem necessariamente levarem em conta dados objetivos e tangíveis. A esse respeito, Assis e Amaral (2013) reforçam a importância da valorização de indicadores tangíveis das condições de oferta dos cursos nos processos de avaliação da qualidade das IES, em detrimento da utilização de ranqueamentos simplificadores de avaliações complexas e multifacetadas.

Outras modificações introduzidas pela NT n. 16 de 2017 referem-se à importância atribuída aos requisitos relativos a intercâmbio, com a previsão de indicadores relativos à internacionalização de discente, docentes e disciplinas; avanços tecnológicos e práticas inovadoras; estabelecimento de convênios com organizações e instituições; presença de normas institucionalizadas e consolidadas, reconhecidamente exitosas ou inovadoras.

Por fim, a partir de 2017, introduziram-se alterações nos novos instrumentos relativas ao número de indicadores e aos pesos distribuídos nas dimensões para IES (Tabela 1) e cursos de graduação (Tabela 2).

A Tabela 1 mostra os pesos e número de indicadores das dimensões do Sinaes para atos regulatórios de IES, estabelecidos pelas Portarias MEC n. 92/2014 e MEC n. $1382 / 2017$.

Tabela 1 - Pesos e número de indicadores das dimensões do Sinaes para atos regulatórios de IES

\begin{tabular}{|c|c|c|c|c|c|c|c|}
\hline \multirow{3}{*}{ Dimensões } & \multicolumn{3}{|c|}{ Portaria MEC no 92/2014 } & \multicolumn{4}{|c|}{ Portaria MEC n 1.382/2017 } \\
\hline & \multirow{2}{*}{$\begin{array}{c}\begin{array}{c}\text { Credencia } \\
\text { mento }\end{array} \\
\text { Peso }\end{array}$} & \multirow{2}{*}{\begin{tabular}{|c|}
$\begin{array}{c}\text { Recredencia } \\
\text { mento }\end{array}$ \\
Peso \\
\end{tabular}} & \multirow{2}{*}{$\begin{array}{c}\text { № } \\
\text { indicadores* }\end{array}$} & \multicolumn{2}{|c|}{ Credenciamento } & \multicolumn{2}{|c|}{ Recredenciamento } \\
\hline & & & & Peso & \begin{tabular}{|c|} 
№ \\
indicadores*
\end{tabular} & Peso & $\begin{array}{c}\text { № } \\
\text { indicadores* }\end{array}$ \\
\hline $\begin{array}{l}\text { 1. Planejamento e } \\
\text { Avaliação Institucional }\end{array}$ & 10 & 10 & 5 & 10 & 3 & 10 & 5 \\
\hline $\begin{array}{l}\text { 2. Desenvolvimento } \\
\text { Institucional }\end{array}$ & 20 & 20 & 9 & 30 & 7 & 30 & 7 \\
\hline 3. Políticas Acadêmicas & 20 & 30 & 13 & 20 & 10 & 10 & 12 \\
\hline 4. Políticas de Gestão & 20 & 20 & 8 & 20 & 7 & 20 & 8 \\
\hline 5. Infraestrutura & 30 & 20 & 16 & 20 & 18 & 30 & 18 \\
\hline
\end{tabular}

Fonte: construído pelos autores, com informações de Portaria MEC $n^{\circ}$ 92/2014 e Portaria MEC $n^{\circ}$ $1.382 / 2017$.

A Portaria MEC no 92/2014 possuía um único instrumento para os atos de credenciamento e recredenciamento de IES, vigorando somente para a modalidade presencial. Por sua vez, a Portaria MEC $n^{\circ} 1.382 / 2017$ possui dois instrumentos, um para cada ato autorizativo mencionado, com validade para as modalidades presencial e a distância. Para os atos de credenciamento e recredenciamento institucional, a Tabela 1 retrata uma mudança pequena entre os dois últimos instrumentos vigentes na quantidade de indicadores das diferentes dimensões, notando-se, entretanto, uma diminuição nos números de indicadores. No que se refere aos pesos, observa-se uma valoração da dimensão "Desenvolvimento Institucional" no instrumento de 2017 e uma diminuição considerável da dimensão "Políticas Acadêmicas" quando se compara os atos de permanência dos anos de 2014 e 2017. 
A Tabela 2 mostra os pesos e quantitativos de indicadores das dimensões do Sinaes associados aos atos regulatórios de cursos de graduação presentes nas Portarias MEC n. 386/2016 e MEC n. 1.383/2017.

Tabela 2 - Pesos e número de indicadores das dimensões do Sinaes para atos regulatórios de cursos de graduação

\begin{tabular}{|c|c|c|c|c|c|c|c|}
\hline \multirow{3}{*}{ Dimensões } & \multicolumn{3}{|c|}{ Portaria MEC no 386/2016 } & \multicolumn{4}{|c|}{ Portaria MEC no 1.383/2017 } \\
\hline & \multirow{2}{*}{\begin{tabular}{|c} 
Autorização \\
Peso
\end{tabular}} & \multirow{2}{*}{$\begin{array}{c}\begin{array}{c}\text { Recon. e } \\
\text { renov. }\end{array} \\
\text { Peso }\end{array}$} & \multirow{2}{*}{$\begin{array}{c}\text { № } \\
\text { indicadores }\end{array}$} & \multicolumn{2}{|c|}{ Autorização } & \multicolumn{2}{|c|}{ Recon. e renov. Recon } \\
\hline & & & & Peso & $\begin{array}{c}\text { № } \\
\text { indicadores } \\
\end{array}$ & Peso & $\begin{array}{c}\text { № } \\
\text { indicadores } \\
\end{array}$ \\
\hline $\begin{array}{l}\text { 1. Organização Didático- } \\
\text { Pedagógica }\end{array}$ & 30 & 40 & 36 & 40 & 24 & 30 & 24 \\
\hline $\begin{array}{l}\text { 2. Corpo Docente e } \\
\text { Tutorial }\end{array}$ & 30 & 30 & 21 & 20 & 15 & 40 & 16 \\
\hline 3. Infraestrutura & 40 & 30 & 23 & 40 & 16 & 30 & 18 \\
\hline
\end{tabular}

Fonte: construído pelos autores, com informações de Portaria MEC n 386/2016 e Portaria MEC nº $1.383 / 2017$.

Para analisar a Tabela 2, deve-se mencionar que a Portaria MEC n 386/2016 teve seus efeitos suspensos pouco mais de 4 meses após a sua aprovação e, durante este período e até a publicação do instrumento de avaliação, presente na Portaria MEC $n$. $1383 / 2017$, foi utilizado o instrumento disponibilizado pelo Inep em 2015. Dessa forma, a Portaria n. 386/2016, suspensa, retrata uma perspectiva de atuação que se refere à avaliação in loco e que não foi implementada de fato. Ainda, a Portaria MEC $n^{\circ}$ 386/2016 prevê um único instrumento para os atos de autorização, reconhecimento e renovação de reconhecimento de cursos. Por sua vez, a Portaria MEC no 1.383/2017 possui dois instrumentos para os referidos atos, um para autorização e outro para reconhecimento e renovação de reconhecimento, sendo que ambos os dispositivos legais já mencionavam a unificação entre os instrumentos das modalidades presencial e a distância.

$\mathrm{Na}$ Tabela 2, para as três dimensões, organização didático-pedagógica, corpo docente e infraestrutura, ocorreu uma diminuição considerável no número de indicadores e uma mudança nos pesos das dimensões 1 e 2, nos dois últimos instrumentos vigentes. Em especial, na dimensão corpo docente, os atos de entrada e permanência atribuíam a essa dimensão o mesmo peso $30 \mathrm{em} \mathrm{2016.} \mathrm{Em} \mathrm{2017,} \mathrm{ela} \mathrm{passou} \mathrm{a} \mathrm{pesar} \mathrm{20,} \mathrm{no} \mathrm{ato} \mathrm{de}$ entrada, e 40 no de permanência. $O$ argumento para isto é que, para os atos de entrada, 0 que se tem do corpo docente é apenas um termo de compromisso e que, no ato de permanência, espera-se que a relação de trabalho entre a IES e o seu corpo docente apresente-se mais qualificada e, portanto, mereça um peso maior.

Há que se destacar, para essa dimensão, a mudança significativa nos pesos em 2017, momento no qual ela passou a ser avaliada por critérios completamente subjetivos, e ainda pelo fato de essa mudança ter provocado a diminuição do peso da dimensão "Organização didático-pedagógica" para o ato autorizativo de permanência no sistema. Justamente no momento em que se esperava uma valoração especial dessas dimensões tão caras ao processo ensino-aprendizagem. 
Os recentes instrumentos revisam a avaliação externa in loco com vistas a adequá-la às novas demandas que direcionam o perfil e a atuação das IES na oferta de educação superior. Neste caso, observa-se um fortalecimento do papel dos órgãos colegiados da IES, responsáveis por construir os relatórios com as evidências necessárias para fundamentar o processo avaliativo. Dessa forma, por meio de seus colegiados, a própria IES atribui a sua qualidade, sem a participação das comissões externas de especialistas, responsáveis pela verificação in loco. Registre-se, portanto, uma mudança no papel destas comissões, na medida em que a avaliação se tornou mais qualitativa, baseadas em análises subjetivas.

Por fim, na tentativa de resolver os problemas decorrentes desta transição de modelos, de modo que os resultados das avaliações pudessem ser disponibilizados de forma mais clara e precisa, e para que IES ou cursos não fossem colocados em faixas que não retratassem as suas características efetivas, a Nota Técnica $n^{0}$ 16/2017/CGACGIES/DAES determinou que os conceitos de avaliação, Conceito de Curso e Conceito Institucional fossem disponibilizados também de forma contínua.

Por todo o exposto, observa-se que a legislação que dispõe sobre a avaliação externa in loco vem sofrendo mudanças substanciais desde a criação do Sinaes e, a partir de 2017, as alterações nos instrumentos de avaliação tornaram os critérios mais subjetivos, ao mesmo tempo, os procedimentos relativos à avaliação, regulação e supervisão da educação superior se tornaram menos exigentes e mais flexíveis, o que fortalece os argumentos de uma flexibilização dos processos de avaliação e em uma consequente (des)regulação do campo pelo poder público. Neste sentido, a qualidade da educação superior entra em evidência, uma vez que essa flexibilização de procedimentos e a subjetividade dos critérios de avaliação enfraquecem as bases nas quais o Sinaes ${ }^{12}$ se sustentou desde a sua criação, em 2004.

Isto pode ser vislumbrado na medida em que se discute a preocupação das IES em adaptar sua realidade institucional aos parâmetros das dimensões avaliadas. A este respeito, Dias Sobrinho (2010, p. 195) alerta que a avaliação "produz mudança curricular, nas metodologias de ensino, nos conceitos e práticas de formação, na gestão, nas estruturas de poder, nos modelos institucionais, [...] nas políticas de pesquisa, nas noções de pertinência e responsabilidade social".

Embora fora das mudanças legais e normativas do campo da avaliação educacional, a Emenda Constitucional no 95 de 2016, sobre o novo regime fiscal para o Brasil, já no período Temer, dispõe sobre o congelamento das despesas primárias do Poder Executivo, o que, inevitavelmente, atingirá as áreas de educação e saúde. Nesse caso, haverá a inviabilização do alcance das metas e estratégias do PNE (AMARAL, 2016). É com esta lógica que, além da falta de planejamento de longo prazo, as políticas educacionais têm sido "circunscritas à perspectiva governamental, não assumindo escopo mais abrangente como política de Estado", o que imbui uma lógica "na qual a descontinuidade é um simulacro da continuidade" (DOURADO, 2010; 2018, p. 479).

A educação, como direito social fundamental do cidadão e como ato político, é permeada por diferentes concepções, com disputas de ideias e de projetos. Por conseguinte, de acordo com Dourado (2010) "o campo educacional é demarcado por posições políticas não apenas diferentes, mas substantivamente contraditórias". Com este entendimento, deve-se considerar que "...a avaliação de uma política pública é sempre resultante das condições objetivas em que ela é proposta e/ou efetivada" (DOURADO, 
2010, p. 678;680). Ainda, para assimilar as relações necessárias para a sua implementação, o mesmo autor relata que é preciso:

\begin{abstract}
...destacar que as imbricações entre a realidade social dinâmica e os atores sociais são permeadas por categorias analíticas (teóricoconceituais) e procedimentos políticos (fins visados), cuja materialização se efetiva na intersecção entre regulamentação, regulação e ação política, marcados por disputas que traduzem os embates históricos entre as classes sociais e, ao mesmo tempo, os limites estruturais que demarcam as relações sociais capitalistas (DOURADO, 2010, p. 679).
\end{abstract}

Ademais, consideramos que o debate sobre políticas públicas, dentre elas as educacionais, requer o conhecimento de que não existe relação linear entre proposição e materialização, ou seja, nem sempre o que foi proposto é realmente implementado. Por ser um espaço de disputas e de contradições, com posições políticas divergentes, há uma série de aspectos que devem ser considerados, como, os atores e as disputas envolvidos, o processo de regulação e as condições objetivas para a sua concretização.

\title{
CONSIDERAÇÕES FINAIS
}

As dinâmicas reservadas ao Sinaes, como política de Estado, carregam o período turbulento transcorrido de 2014 até 2018 em suas alterações legais e normativas. Neste mesmo período, o PNE deveria se constituir no "epicentro" das decisões tomadas para o campo da educação até 2024 (DOURADO, 2017). Entretanto, o que se percebe é uma ruptura drástica nas políticas educacionais, que vêm desconsiderando o proposto nas metas do PNE. No campo da avaliação, foco deste estudo, o que se observou foi uma crescente flexibilização dos processos de avaliação, com consequente (des) regulação do campo pelo poder público, com decisão mais centralizadas diretamente ao gabinete do Ministro da Educação e menos às respectivas secretarias deste Ministério, dando ideia de que, desta forma, estão atendendo a uma histórica demanda pela desburocratização do sistema. Entretanto, o que de fato está em curso é uma redução do papel do Estado nos processos de regulação, o que favorece as IES privadas mercantis ${ }^{13}$, cujas condições de oferta educacional são pensadas mais em função do lucro e do acúmulo de capital do que na qualidade dos cursos oferecidos. A esse respeito recorremos a lanni para quem

o Estado tende a secundarizar as condições institucionais e os "processos sociais, políticos e culturais [educacionais]" em benefício dos processos que visam a acumulação do capital e que determinam e orientam o essencial das atividades estatais. Entre as principais funções do Estado na relação com o capital destacar-se-ia a "dinamização das virtualidades do sistema de mercado" (IANNI, 2004, p. 18).

Quanto aos pontos de alteração das legislações em 2016 e 2017, observa-se que expressam continuidades e descontinuidades entre si e em relação ao inicialmente 
proposto pelo Sinaes, em 2004. As novas legislações que reformularam o Sinaes, em 2016, pretendiam trazer uma nova perspectiva, já prevista nas estratégias 12.19 e 13.1 do PNE 2014-2024. Entretanto, as mudanças consideráveis nos critérios relativos às avaliações externas in loco trazem uma simplificação muito grande, que dispensa a presença de visita dos avaliadores. Exemplo disso é a (re)unificação dos instrumentos de avaliação, para as modalidades presencial e a distância, que surgem separados nos primórdios do Sinaes, são unificados em 2011 e novamente separados nas legislações revogadas de 2016.

O MEC explicita que as alterações mencionadas basearam-se em leis pertinentes, na legislação recentemente instituída, em estudos estatísticos, em análise de demandas provenientes da sociedade civil organizada e da comunidade acadêmica. Enfatiza também que atendem às metas do PNE, à interlocução com os integrantes do Banco Nacional de Avaliadores do Sinaes - BASis, além de manterem um permanente diálogo com o Inep e a Seres, que utilizam os instrumentos em sua prática regulatória (BRASIL, 2017).

A flexibilização e a (des)regulamentação também aparecem nas alterações legais e normativas aplicadas ao Sinaes, quando apresentam concessões de autonomia e de autorregulação, a partir de apreciações mais subjetivas ao gosto das IES privadas. $O$ que está por trás da concessão de autonomia e de autorregulação é uma associação com as noções de desregulamentação rumo à plena e livre mercantilização da Educação Superior, via Estado mínimo, o que não guarda relação alguma com a noção de autonomia que fez e faz parte das bandeiras levantadas para a atuação das universidades.

Nas primeiras ações do governo Bolsonaro voltadas à educação, em 2019, assistiu-se a ataques dirigidos às Universidades Públicas, principalmente, às Universidades e Instituições Federais, classificando-as como perdulárias, promotoras de pesquisas sem nenhum sentido prático e de "eventos ridículos", dominados por pessoas "marxistas", dentre outras declarações polêmicas"14.

Somam-se a estes ataques o desdém pelas ciências humanas, em especial à Sociologia e à Filosofia. O MEC ainda utilizou o orçamento público das federais para fazer chantagens por meio de cortes/contingenciamentos ao longo do ano de 2019, como estratégia para tentar aprovar um projeto que denominou de "Future-se" principal repousa na quebra da autonomia universitária. Há forte resistência a essa tentativa de desmonte das universidades federais e o projeto do MEC segue tramitando, sem perspectivas concretas de aprovação. Entretanto, com tanta campanha difamatória produzida pelo MEC, impulsionada pelas mídias digitais, os estragos à imagem das Universidades e Institutos Federais já podem ser muito grandes e às vezes irreparáveis em curto prazo, o que poderá facilitar a implementação de mudanças nas legislações relacionadas ao processo avaliativo vinculado ao Sinaes.

No campo da avaliação da Educação superior, o que se anuncia é mais simplificação, flexibilização, (des)regulamentação dos atos autorizativos condicionados à avaliação de desempenhos pelo poder público, a partir de mudanças que intensificam a (de)formação do Sinaes em seu ciclo da política. Todas estas mudanças são atravessadas pelas tensões das disputas e embates, desde a Lei 13.005 de 2014 do PNE.

Os antagonismos que marcaram esses últimos anos do Sinaes e o cenário estabelecido para os próximos anos nos permitem perguntar: está próximo o fim do ciclo de vida da política do Sinaes? 


\title{
EVALUATION OF HIGHER EDUCATION AND NATIONAL EDUCATION PLAN: TENSIONS, CHANGES AND PERSPECTIVES
}

\begin{abstract}
This study aims to problematize the dynamics of public policies aimed at the evaluation, regulation, and supervision of Brazilian Higher Education, by relating them to Goals 12, 13, and 14 of the National Education Plan (PNE) and, especially, to strategies related to the National Higher Education Assessment System (Sinaes), Law no. 10,861 of 2004. This is a theoretical and documentary study, anchored in Dourado (2017 and 2018); Barreyro and Rothen (2006 and 2011); Dias Sobrinho (2010); Amaral (2016 and 2019) among others, in addition to normative texts on Sinaes. The study revealed that the field of higher education evaluation has been going through processes of flexibility and (de)regulation of authorizing acts based on changes that intensify the (de)formation of Sinaes in its policy cycle. All these changes are crossed by tensions, disputes, and conflicts since Law 13,005 of 2014 of the PNE, marked and influenced by an unstable political scenario and unfavorable to social and educational policies.
\end{abstract}

KEYWORDS: National Education Plan. Higher education. Evaluation. Sinaes.

\section{EVALUACIÓN DE LA EDUCACIÓN SUPERIOR Y PLAN NACIONAL DE EDUCACIÓN: TENSIONES, CAMBIOS Y PERSPECTIVAS}

RESUMEN: Este estudio tiene como objetivo problematizar la dinámica de las políticas públicas orientadas a la evaluación, regulación y supervisión de la Educación Superior brasileña, relacionándolas con las Metas 12, 13 y 14 del Plan Nacional de Educación (PNE) y, especialmente, con las estrategias relacionadas al Sistema Nacional de Evaluación de la Educación Superior (Sinaes) Ley 10.861 de 2004. Se trata de un estudio teórico y documental, anclado en Dourado (2017 y 2018); Barreyro y Rothen (2006 y 2011); Dias Sobrinho (2010); Amaral (2016 y 2019) entre otros, además de textos normativos sobre Sinaes. El estudio reveló que el campo de la evaluación de la educación superior ha venido atravesando procesos de flexibilización y (des)regulación de actos de autorización basados en cambios que intensifican la (des)formación del Sinaes en su ciclo de políticas. Todos estos cambios están atravesados por tensiones, disputas y conflictos desde la Ley 13.005 de 2014 del PNE, marcados e influenciados por un escenario político inestable y desfavorable para las políticas sociales y educativas.

PALABRAS CLAVE: Plan Nacional de Educación. Educación más alta. Evaluación. Sinaes.

\section{NOTAS}

1) Censo da Educação Superior 2012-2016, Pnad/IBGE 2012-2015 e Pnac/4 trim. Dados levantados no âmbito do Projeto Integrado de Pesquisa "Expansão e qualidade da educação superior no 
contexto do Plano Nacional de Educação (2014-2024): tensões, limites e perspectivas", UFG/UFRN, financiado pelo CNPq.

2) A primeira experiência mais ampla de avaliação da educação superior no Brasil ocorreu na década de 1980, quando "se realizou experiências de auto avaliação em diversas instituições brasileiras, como por exemplo, a Universidade de Brasília e a Universidade de São Paulo. No âmbito do MEC foram publicados documentos, dentre os quais "Programa de Avaliação da Reforma Universitária" (de 1983); o Relatório da Comissão Nacional de Avaliação do Ensino Superior intitulado "Uma nova Política para a Educação Superior Brasileira" (1985); "Relatório do Grupo Executivo para a Reformulação da Educação Superior" (1986). [...] Nos anos 1990 implantou-se o Programa de Avaliação das Universidades Brasileiras (Paiub) no âmbito do MEC, seguido do Exame Nacional de Cursos (provão). De acordo com Barreyro e Rothen, "não há continuidade conceitual entre o Paiub e as avaliações que o seguiram, mas o Programa foi precursor da avaliação como política pública" (BARREYRO E ROTHEN, 2011, p. 76-79).

3) 12.19) reestruturar com ênfase na melhoria dos prazos e qualidade da decisão, no prazo de dois anos, os procedimentos adotados na área da avaliação, regulação e supervisão, em relação aos processos de autorização de cursos e instituições, de reconhecimento ou renovação de reconhecimento de cursos superiores e de credenciamento ou recredenciamento de instituições, no âmbito do sistema federal de ensino. 13.1) aperfeiçoar o Sistema Nacional de Avaliação da Educação Superior - Sinaes, de que trata a Lei no 10.861, de 14 de abril de 2004, fortalecendo as ações de avaliação, regulação e supervisão; 13.2) ampliar a cobertura do Exame Nacional de Desempenho de Estudantes - ENADE, de modo a aumentar o quantitativo de estudantes e de áreas avaliadas no que diz respeito à aprendizagem resultante da graduação; 13.3) induzir processo contínuo de auto avaliação das instituições de educação superior, fortalecendo a participação das comissões próprias de avaliação, bem como a aplicação de instrumentos de avaliação que orientem as dimensões a serem fortalecidas, destacando-se a qualificação e a dedicação do corpo docente; 13.4) promover a melhoria da qualidade dos cursos de pedagogia e licenciaturas, por meio da aplicação de instrumento próprio de avaliação aprovado pela Comissão Nacional de Avaliação da Educação Superior - CONAES, integrando-os às demandas e necessidades das redes de educação básica, de modo a permitir aos graduandos a aquisição das qualificações necessárias a conduzir o processo pedagógico de seus futuros alunos (as), combinando formação geral e específica com a prática didática, além da educação para as relações étnico-raciais, a diversidade e as necessidades das pessoas com deficiência; 13.6) substituir o Exame Nacional de Desempenho de Estudantes ENADE, aplicado ao final do primeiro ano do curso de graduação pelo Exame Nacional do Ensino Médio - ENEM, a fim de apurar o valor agregado dos cursos de graduação; 13.8); elevar gradualmente a taxa de conclusão média dos cursos de graduação presenciais nas universidades públicas, de modo a atingir 90 (noventa por cento) e, nas instituições privadas, 75 (setenta e cinco por cento), em 2020; e fomentar a melhoria dos resultados de aprendizagem, de modo que, em 5 (cinco) anos, pelo menos 60 (sessenta por cento) dos estudantes apresentem desempenho positivo igual ou superior a 60 (sessenta por cento) no Exame Nacional de Desempenho de Estudantes ENADE e, no último ano de vigência, pelo menos 75 (setenta e cinco por cento) dos estudantes obtenham desempenho positivo igual ou superior a 75 (setenta e cinco por cento) nesse exame, em cada área de formação profissional. (BRASIL, 2014, p. 22).

4) Que culminou com o golpe jurídico, parlamentar e midiático de 2016 (SOUZA, 2017).

5) Em comparação com a Lei que institui o Sinaes, o Decreto "Ponte" traz como novidade que os atos de credenciamento/autorização e o recredenciamento dos cursos e instituições são de responsabilidade das Secretarias do MEC e do Conselho Nacional de Educação (art. 5 e 6). Em outros aspectos repete a Lei do Sinaes. Segundo Barreyro e Rothen (2006) "com este decreto, a Lei do Sinaes é re-elaborada: por um lado, retoma o princípio da separação entre a regulação e a avaliação e, por outro, reforça a visão da separação entre a auto-avaliação e a avaliação externa, deixando transparecer que esta faz parte do processo de supervisão e regulação. As consequências disto vai [sic] depender de como ele será operacionalizado" (p. 970). 
6) O Decreto $n^{\circ} 8.754 / 2016$, modificou o Decreto $n^{\circ} 5773 / 2006$ para prever, dentre outras questões, que a criação de universidade ou instituto federal dispensaria a edição do ato autorizativo prévio para funcionamento e oferta de cursos, nos termos de sua lei de criação.

7) Antecedido em sete meses pelo Decreto $n^{\circ} 9.057$, de 25 de maio de 2017, que regulamenta o art. 80 da LDB sobre Educação a Distância (EaD) com capítulo III dedicado a essa modalidade no nível da educação superior. Como aconteceu em 2004 e em 2016, também o Decreto de 2017 foi antecedido por decretos direcionados à EaD.

8) As alterações de 2016 já excluíam as competências da SESU, da SEPT e da SEaD, com centralização das ações no MEC e na Seres.

9) Para avaliação in loco de IES, o instrumento inicial foi a Portaria $n^{\circ} 1.016$, de 30 de outubro de 2007 (revogada), que aprovou, em extrato, o Instrumento de Avaliação para Credenciamento de novas IES no Sinaes. Posteriormente, a Portaria no 1.264, de 17 de outubro de 2008 (revogada), aprovou, em extrato, o Instrumento de Avaliação Externa de IES do Sinaes. Em seguida, a Portaria n 92, de 31 de janeiro de 2014 (revogada), aprovou, em extrato, os indicadores do Instrumento de Avaliação Institucional Externa para os atos de credenciamento, recredenciamento e transformação de organização acadêmica, modalidade presencial, do Sinaes. A portaria vigente, que revogou a anterior, é a Portaria MEC n 1.382/2017.

10) Para a avaliação in loco de cursos de graduação, a Portaria MEC no 1.741, de 12 de dezembro de 2011, que aprovou, em extrato, os indicadores do Instrumento de Avaliação de Cursos de Graduação nos graus de tecnólogo, de licenciatura e de bacharelado para as modalidades presencial e a distância, revogou diferentes portarias dos anos de 2007, 2008, 2009 e 2010, época em que os instrumentos de avaliação de cursos não eram unificados, apresentando distintos instrumentos para cursos, modalidades e atos autorizativos diversos. Posteriormente, a Portaria de 2011 foi revogada pela Portaria MEC $n^{\circ}$ 386, de 10 de maio de 2016. Entretanto, em 12 de setembro de 2016, a Portaria MEC no 1.053 alterou e suspendeu os efeitos da Portaria MEC $n^{\circ} 386 / 2016$, retomando os termos da já revogada Portaria MEC n 1.741/2011, enquanto durasse a referida suspensão. Por fim, a Portaria MEC no 1.383/2017 revogou a Portaria MEC n 386/2016.

11) O Indicador de Qualidade do Corpo Docente é um indicador originalmente solicitado pelo Tribunal de Contas da União (TCU) para o cálculo dos indicadores de gestão das IES. Ao expressar a quantidade de professores com titulação de pós-graduação, de forma indireta, o indicador faz uma relação da qualidade do ensino e do volume de pesquisa com a titulação ao supor que, quanto maior a quantidade de professores com titulação, maior a quantidade e melhor a qualidade das pesquisas realizadas na IES.

12) Para fundamentar ainda mais esta percepção, relata-se que em 2018 a Organização para a Cooperação e o Desenvolvimento Econômico - OCDE construiu um relatório intitulado Repensando a Garantia e Qualidade para o Ensino Superior no Brasil, após solicitação do MEC, da CONAES e da CAPES, com o objetivo de avaliar a relevância, a eficácia e a eficiência dos procedimentos em vigor para as políticas federais de garantia de qualidade para o ensino superior, para graduação e pósgraduação (OCDE, 2018). O INEP elaborou uma análise do referido documento, tecendo críticas à metodologia empregada para a sua construção e discutiu, em especial, as sugestões da OCDE no que se refere à avaliação in loco: criação de agência que agregue as funções previstas para a Seres e para a Daes; criação de um portal com informações sobre IES e cursos que passaram por avaliação; atribuição de status de "auto-credenciamento" para IES que demonstrarem possuir qualidade; adoção de medidas para melhorar o processo de avaliação de cursos que ainda tenham que passar por avaliações de autorização e de reconhecimento (BRASIL, 2019).

13) A esse respeito conferir o estudo de SGUISSARDI, Valdemar. Educação Superior no Brasil. Democratização ou massificação mercantil? Educação e Sociedade, v. 36, n. 133, 2015.

14) Conferir em: https://g1.globo.com/jornal-nacional/noticia/2019/05/01/declaracao-do-ministroda-educacao-sobre-universidades-gera-criticas-de-especialistas.ghtml. Acesso em: 30 jan. 2019. 
ASSIS, L. M. de COSTA, A. L. C.; LOPES, P. I. X.; GOMES, D. F.

15) A esse respeito consultar AMARAL, Nelson Cardoso. Contrato de Desempenho da nova versão do Future-se NÃO deve ser assinado. Para esse autor "Ao estabelecer a presença de "indicadores de desempenho" associados aos três eixos do Programa, isto traria uma série de "desobediências" ao Art. 207 (CF), uma vez que a universidade ficará tolhida de sua autonomia constitucional pela "imposição" de indicadores que desobedecem a diversas dimensões da autonomia: didáticocientífica, administrativa e de gestão financeira e patrimonial".

\section{REFERÊNCIAS}

AMARAL, Nelson Cardoso. Contrato de Desempenho da nova versão do Future-se NÃO deve ser assinado. Disponível em: https://jornal.ufg.br/n/121422-contrato-dedesempenho-da-nova-versao-do-future-se-nao-deve-ser-assinado. Acesso em: 29 jan. 2020.

AMARAL, Nelson Cardoso. PEC 241/55: a "morte" do PNE 2014-2024 e o poder de diminuição dos recursos educacionais. Goiânia: RBPAE, v. 32, n. 3, p. 653-673, set./dez. 2016.

ASSIS, Lúcia Maria de; AMARAL, Nelson Cardoso. Avaliação da Educação: por um sistema nacional. RETRATOS DA ESCOLA, v. 7, n. 12, jan./jun. 2013. Brasília: CNTE, 2013.

BRASIL. Ministério da Educação. Instituto Nacional de Estudos e Pesquisas Educacionais Anísio Teixeira. Instrumento de Avaliação Institucional Externa presencial e a

distância: recredenciamento, transformação de organização acadêmica. Brasília, 2017. Disponível em:

http://download.inep.gov.br/educacao superior/avaliacao institucional/instrumentos/2 017/IES recredenciamento.pdf. Acesso em: 19 fev. 2018.

BRASIL. Ministério da Educação. Instituto Nacional de Estudos e Pesquisas Educacionais Anísio Teixeira. Análise do documento “Repensar da garantia da qualidade da educação superior no Brasil. [2019]. Disponível em:

http://download.inep.gov.br/acoes internacionais/ocde/Consideracoes OCDE 122018. pdf. Acesso em: 01 dez. 2019.

BARREYRO, Gladys Beatriz \& ROTHEN, José Carlos. Avaliação da Educação Superior como política pública. In: ROTHEN, José Carlos \& BARREYRO, Gladys Beatriz. Avaliação da Educação: diferentes abordagens críticas. São Paulo: Xamã, 2011.

BARREYRO, Gladys Beatriz \& ROTHEN, José Carlos. "Sinaes" contraditórios: considerações sobre a elaboração e implantação do Sistema Nacional de Avaliuação da educação Superior. Educ. Soc., Campinas, v. 27, n. 96, p. 955-977, out. 2006.

DIAS SOBRINHO, José. Avaliação e transformações da educação superior brasileira (1995-2009): do provão ao Sinaes. Avaliação. Campinas, Sorocaba, SP, v.15, n.1, p.195224, mar. 2010. 
DOURADO, Luiz Fernandes. Avaliação do Plano Nacional de Educação 2001-2009: 
questões estruturais e conjunturais de uma política. Educ. Soc., Campinas, v. 31, n. 112, p. 677-705, jul.-set. 2010. Disponível em: http://www.scielo.br/pdf/es/v31n112/03. Acesso em: 10 ago. 2018.

DOURADO, Luiz Fernandes. Plano Nacional de Educação: o Epicentro das políticas de Estado para a educação brasileira. Goiânia: Editora Imprensa Universitária / ANPAE, 2017.

DOURADO, Luiz Fernandes. A Institucionalização do Sistema Nacional de Educação e o Plano Nacional de Educação: proposições e disputas. Educ. Soc., Campinas, v. 39, n. 143, p. 477-498, jun. 2018. Disponível em: http://www.scielo.br/scielo.php?script=sci arttext\&pid=S010173302018000200477\&lng=pt\&nrm=iso. Acesso em: 29 jan. 2019. http://dx.doi.org/10.1590/es0101-73302018203079.

IANNI, Octavio. Estado e Capitalismo. 2. ed. São Paulo: Ed. Brasiliense, 2004.

OCDE. Organização para a Cooperação e o Desenvolvimento Econômico. Repensando a Garantia de Qualidade para o Ensino Superior no

Brasil. OCDE: 2018. Disponível em: http://download.inep.gov.br/acoes internacionais/o cde/Consideracoes OCDE 122018.pdf. Acesso em: 01 dez. 2019.

SGUISSARDI, Valdemar. Educação Superior no Brasil. Democratização ou massificação mercantil? Educ. Soc., Campinas, v. 36, n. 133, p. 867-889, dez. 2015.

SOUZA, Jessé. A Elite do Atraso: da escravidão à Lava jato. Rio de Janeiro: Ed. Leya, 2017.

LúCIA MARIA de Assis: Pedagoga pela Pontifícia Universidade Católica de Minas Gerais (PUC/MG, 1984), mestre em Educação pela Universidade Metodista de Piracicaba, (Unimep, 2001), doutora em Educação pela Universidade Federal de Goiás, (UFG, 2008) e pós-doutora pela Universidade de São Paulo, (USP, 2014). Professora Associada da Faculdade de Educação da Universidade Federal de Goiás na graduação e na pós-graduação (PPGE), na linha de pesquisa Estado, Políticas e História da Educação. Orcid: https://orcid.org/0000-0002-6380-2129

E-mail: luciamariadeassis@gmail.com 
Aline Fagner Carvalho Costa: Doutora em Educação pela UFG, cientista social, docente e gestora na educação superior e profissional. Pesquisadora na área de políticas educacionais. Coordenadora pedagógica do Programa de Educação Ambiental de Trabalhadores (PEAT) em Oriximiná, Pará.

Orcid: https://orcid.org/0000-0002-6576-7486

E-mail: alinefagner@hotmail.com

Pedro IsAac XIMenes LOPES: Doutor em Educação pela UFRN, técnico em assuntos educacionais da UFRN e membro da comissão própria de avaliação CPA. É pesquisador na área de políticas educacionais e docente da Escola de Educação da Universidade Potiguar $\left(\mathrm{UnP}_{\mathrm{P}}\right)$.

Orcid: https://orcid.org/0000-0003-0788-8842

E-mail: pedro_isaac@ct.ufrn.br

Daniela Ferndandes Gomes: Doutoranda em Educação pela Universidade Federal de Goiás (UFG) na linha de pesquisa Estado, Políticas e História da Educação. Mestre em Educação pela UnB. Técnica em assuntos educacionais da pró-reitoria de ensino do Instituto Federal do Norte de Minas Gerais (IFNMG). Pesquisa avaliação e qualidade da educação superior.

Orcid: https://orcid.org/0000-0002-8931-8837

E-mail: danielafs1412@smail.com

Este periódico utiliza a licença Creative Commons Attribution 3.0, para periódicos de acesso aberto (Open Archives Iniciative - OAI). 